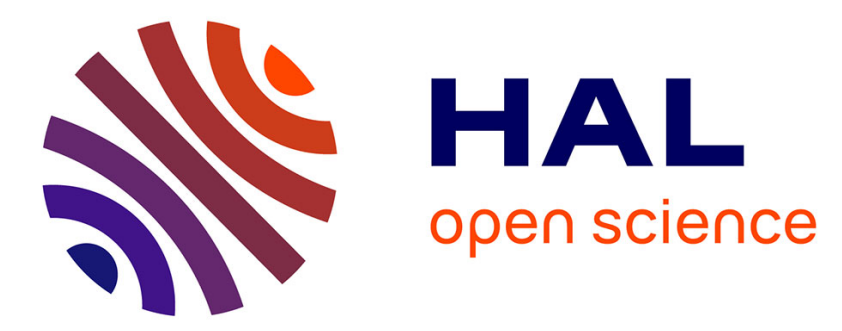

\title{
Physiological mechanisms explaining human differences in fat perception and liking in food spreads-a review
}

Elisabeth Guichard, Veronica Galindo-Cuspinera, Gilles Feron

\section{To cite this version:}

Elisabeth Guichard, Veronica Galindo-Cuspinera, Gilles Feron. Physiological mechanisms explaining human differences in fat perception and liking in food spreads-a review. Trends in Food Science and Technology, 2018, 74, pp.46-55. 10.1016/j.tifs.2018.01.010 . hal-02620994

\section{HAL Id: hal-02620994 \\ https://hal.inrae.fr/hal-02620994}

Submitted on 26 May 2020

HAL is a multi-disciplinary open access archive for the deposit and dissemination of scientific research documents, whether they are published or not. The documents may come from teaching and research institutions in France or abroad, or from public or private research centers.
L'archive ouverte pluridisciplinaire HAL, est destinée au dépôt et à la diffusion de documents scientifiques de niveau recherche, publiés ou non, émanant des établissements d'enseignement et de recherche français ou étrangers, des laboratoires publics ou privés.

\section{다)(1) $(5$}

Distributed under a Creative Commons Attribution - NonCommerciall 4.0 International 


\section{Accepted Manuscript}

Physiological mechanisms explaining human differences in fat perception and liking in food spreads-a review

Elisabeth Guichard, Veronica Galindo-Cuspinera, Gilles Feron

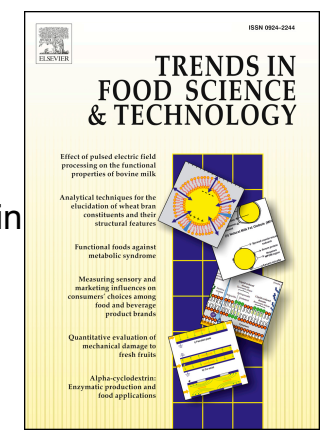

PII:

S0924-2244(17)30633-7

DOI:

10.1016/j.tifs.2018.01.010

Reference: TIFS 2152

To appear in: Trends in Food Science \& Technology

Received Date: 28 September 2017

Revised Date: 29 December 2017

Accepted Date: 23 January 2018

Please cite this article as: Guichard, E., Galindo-Cuspinera, V., Feron, G., Physiological mechanisms explaining human differences in fat perception and liking in food spreads-a review, Trends in Food Science \& Technology (2018), doi: 10.1016/j.tifs.2018.01.010.

This is a PDF file of an unedited manuscript that has been accepted for publication. As a service to our customers we are providing this early version of the manuscript. The manuscript will undergo copyediting, typesetting, and review of the resulting proof before it is published in its final form. Please note that during the production process errors may be discovered which could affect the content, and all legal disclaimers that apply to the journal pertain. 


\section{Physiological mechanisms explaining human differences in fat perception}

2 and liking in food spreads-a review.

\section{GUICHARD Elisabeth $^{1 *}{ }^{*}$, GALINDO-CUSPINERA Veronica ${ }^{2}$, FERON Gilles $^{1}$}

${ }^{1}$ Centre des Sciences du Goût et de l'Alimentation, AgroSupDijon, CNRS, INRA, University Bourgogne Franche-Comté, F-21000 Dijon, France.

${ }^{2}$ Unilever R\&D Vlaardingen, Olivier van Noortlaan 120, 3133 AT Vlaardingen, The Netherlands.

*corresponding author: Guichard Elisabeth: elisabeth.guichard@inra.fr

\section{Abstract}

\section{Background}

Fat perception and liking are the subjects of growing interest from industries and the scientific community to reduce the fat content in food products while maintaining consumers' liking.

\section{Scope and Approach}

In this review, the different physiological parameters involved in fat perception and fat liking for food emulsions are explored, focusing on spreads. A deeper analysis of the physiological mechanisms occurring during the melting and inversion phases, followed by bolus formation, mouth coating and oral clearance, allows an examination of the links between food composition, food structure, oral physiological parameters, fat perception and liking.

\section{Key Findings and Conclusions}

Fat perception is a multimodal sensation involving olfactory, gustatory and tactile cues. The main sensory descriptors associated with fat liking are creaminess, spreadability and aroma perception. During the melting and inversion phases, oral volume, saliva flow and tonguepalate compression contribute to the heat transfer and cooling effect, leading to the first sensory perception. Global acceptability is also driven by the mouthfeel sensation perceived 
after swallowing. Mouthfeel is a consequence of the bolus formation, mouth coating and oral clearance processes that are dependent on both emulsion composition and oral physiological parameters (saliva flow, saliva composition, fungiform papillae). Understanding the physiological mechanisms controlling fat perception can lead to a better understanding of the consumer's preference and liking for food emulsions.

\section{Key words}

Fat perception; liking; melting; food bolus; oral physiology; food emulsions.

\section{Highlights}

Fat is multimodal perception involving olfaction, taste and tactile modalities

Fat liking is related to creaminess, spreadability, fluidness, flavour and colour

Melting is the first step in the mouth leading to cooling sensation and liking

Bolus formation is driven by food composition, structure modulated by oral physiology

Saliva flow and composition, oral volume and tongue palate compression are important

\section{Introduction}

Most developed and developing countries are confronted with a rising rate of nutrition-related pathologies, especially obesity, cardiovascular diseases, and diabetes, which are related to unbalanced diets with an excess consumption of fat, salt and sugars. A significant reduction of these food ingredients will contribute both to saving lives and reducing healthcare costs and is the subject of growing interest from both industries and the scientific community.

Despite numerous studies relating consumer liking with product formulation, differences in consumer perception need to be explored in more detail. One hypothesis is that 
individual oral physiology could better explain differences in fat perception and liking than only food composition and structure. Moreover, fat perception is considered a multimodal sensation in itself that involves smell, taste and texture perception (Mattes, 2009; Schiffman, Graham, Sattely-Miller, \& Warwick, 1998). As an example, fat perception in cottage cheeses was found to be driven by a creamy aroma and greasy film (Martin, et al., 2016). Thus, a need exists to consider the different sensory modalities of fat perception.

The aim of this review was first to present the different modalities involved in fat perception and liking when consuming spreads and related food products and then to explore the oral physiological parameters that could be involved in the different oral modalities and analyse the previously examined links between food composition and structure, oral physiological parameters, fat perception and liking.

\section{The different sensory modalities of fat perception}

\subsection{Main sensory descriptors involved in fat perception and liking in food emulsions}

Consumer liking for fat products seems to be driven by textural sensory descriptors (spreadability, meltability, fluidness, and creaminess), flavour and colour. For water-in-oil (W/O) food spreads, appearance can be characterized by colour, gloss and transparency. Even if appearance will not be further investigated in the present review, it has to be mentioned that these sensory attributes can modify consumers' global perception and liking of products. Many studies, but not all, have shown that changing the hue and/or intensity of the colour added to a food or beverage can influence the perceived identity and/or intensity of the flavour (Spence, 2015; Spence et al 2010). Translucency or transparency can affect the overall appearance and can influence liking of foods. Studies conducted on low fat-cheese have shown that liking of low-fat cheese was negatively influenced when the cheese appearance 
was too translucent or too white (Wadhwani, 2012). Krause et al. mentioned that butter liking (evaluated on white bread) was associated with its desirable flavour and colour intensity and was viewed by most consumers (focus group with a questionnaire) as a tasty and natural product (Krause, Lopetcharat, \& Drake, 2007). In this study, the majority of the consumers tested preferred a light-yellow colour for butter, while margarine was described as having a distinctive deeper yellow colour. An evaluation of spread (butter, margarine and two other spreads) liking consumed during a complete meal was conducted by Michicich (Michicich, Vickers, Martini, \& Labat, 1999); their research found that butter was the most preferred spread, margarine was the least preferred, and the similarity between the other spreads and butter was mainly driven by flavour and not by texture. Because spreads are mainly consumed on bread, Coic et al. (Coic, Groeneschild, \& Tournier, 2014) validated that the testing of spreads on bread rather than alone in a spoon was more suitable to study differences in aroma perception and, more specifically, intensity and aftertaste. s Other parameters, such as adhesiveness to spoon, meltability, flouriness and graininess, are negatively correlated to spread liking, as was observed for peanut spreads evaluated on bread (Yeh, Resurreccion, Phillips, \& Hung, 2002). In another study conducted on different fat products, including spreads, the most important descriptors for the overall liking of spreads on bread were found to be "melting", "water release", "oil mass transport" and "lubrication", while an analysis of consumer segment preference for mayonnaise confirmed that sensory fattiness of the spread on the bread system was influenced by additional factors than the fat level only (van den Oever, 2006). In this study, "salty taste", "saliva" and "creamy mouthfeel” were positively associated with spread on bread liking, whereas chew force and stickiness were negatively associated.

The examples presented above indicate that fat perception during consumption involves different sensory modalities: olfactive, gustative, tactile and visual. Before exploring 
the physiological mechanisms involved in the oral perception of fat, the following sections will present the different components of oral fat perception (excluding visual) together with the multimodal interactions between fat perception and other oral sensory modalities.

\subsection{The olfactive modality of fat perception}

Many volatile compounds have been described with a fatty odour note (Leffingwell, 2013). These compounds belong to different chemical classes, esters, aldehydes, ketones, lactones and alcohols, and present different molecular weight and hydrophobicity values. However, within each chemical class, short-chain compounds convey mostly fruity or green notes, and the fatty odour character increases only as the number of carbon atoms rises, as it is the case for octanal, delta nonalactone, methyl decanoate (Jelen \& Gracka, 2017). Moreover, diacetyl (2,3-butanedione) and acetoin (3-hydroxy-2-butanone), which are the main aroma compounds present in a creamy aroma, are not described with fatty odours but only with butter and creamy odours (Thomsen, et al., 2012). The direct relationship between the presence of such an odorant compound in a food product and fat perception of the product is thus not easily established. For example, Charles et al. (Charles, Rosselin, Sauvageot, Beck, \& Guichard, 2000) found no direct relationship between the presence of diacetyl, a compound with a butter odour, and perception of a buttery aroma. They explained this discrepancy by the perception of an odour note being due to a mixture of different volatile compounds. An alternative explanation is that odour perception cannot be directly linked to the concentration of the odorant molecules in food. Odorants are volatile molecules present in the air phase at room and consumption temperature and have to reach the olfactory receptors to be perceived. However, their release from the food matrix into the air phase highly depends on their interaction with non-volatile compounds present in the food matrix (Guichard, 2002). In the present review, we only present interactions between odorants and fat. Because most aroma 
compounds are more soluble in fat than in water, due to their hydrophobic properties, modifications of the nature and concentration of fat in a food product will hence modify the release of aroma compounds into the air phase and thus their accessibility to the olfactory receptors. However, these differences in release behaviour of aroma compounds according to the nature of fat highly depend on the physico-chemical properties of aroma compounds. The most hydrophobic compounds that are more soluble in fat than in water, such as esters, ketones or lactones are less released from spreads with a higher fat content. Their release in the air phase also depends on the nature of the fat. For example, ethyl hexanoate was released more from an oil-in-water $(\mathrm{O} / \mathrm{W})$ emulsion realised with partially hydrogenated palm kernel oil than in emulsions made with anhydrous milk fat, whereas the opposite was found for a less hydrophobic compound, diacetyl (Guichard, Fabre, \& Relkin, 2008). These differences were explained by differences in the polarity of the fats. The most hydrophobic compound, ethyl hexanoate, is more soluble in the more hydrophobic (less polar) fat, which is anhydrous milk fat and thus less released in the air phase. The most polar aroma compound, diacetyl, is more soluble in the more polar fat, which is partially hydrogenated palm kernel oil. The differences in the observed aroma release induced differences in sensory perception, and emulsions realised with partially hydrogenated palm kernel oil were perceived as fruitier due to the higher release of ethyl hexanoate. Moreover, the melting point of fat influenced the volatility of aroma compounds because aroma compounds can only be solubilized in liquid fat. Working on fats differing in their melting points, Roudnitzky et al. showed that ethyl hexanoate, hydrophobic aroma compounds, was better released at a temperature of $15^{\circ} \mathrm{C}$ from anhydrous milk fat with the highest melting point $\left(41^{\circ} \mathrm{C}\right)$, due to the presence of solid fat (Roudnitzky, Irl, Roudaut, \& Guichard, 2003). 
Thus, different odorant compounds are responsible for the olfactive fat modality, but

150

151

152

153

154

155

156

157

158

159

160

161

162

163

164

165

166

167

168

169

170

171

172

173

the amount and nature of the fat can modify their release in the air phase and thus their perception.

\subsection{The taste modality of fat perception}

Fat taste has been principally investigated through the detection of free fatty acids (FFAs) rather than dietary fat and has been the subject of different reviews (Heinze, Preissl, Fritsche, \& Frank, 2015; Running \& Mattes, 2016; Tucker, et al., 2017). Dietary fats are clearly detected in the oral cavity by tactile and retronasal olfactory cues. If there is a gustatory component contributing to the liking of fat as well, free fatty acids are the most likely effective stimuli. When measuring the thresholds of different FFAs based on the C18 carbon chain, differing only in their saturation level (stearic, oleic and linoleic), it was shown that, by removing the olfactive modality (orthonasal and retronasal cues), the FFAs could still be perceived through the taste modality (Chale-Rush, Burgess, \& Mattes, 2007). This finding suggests that FFAs are perceived through gustatory, olfactory and somatosensory cues. In regard to oral physiological parameters and, particularly, saliva, salivary lipolysis has been positively correlated with the FFA threshold in humans (Mounayar, Septier, Chabanet, Feron, \& Neyraud, 2013; Poette, et al., 2014) and negatively correlated with liking (Neyraud, Palicki, Schwartz, Nicklaus, \& Feron, 2012). Moreover, the oral inhibition of lipolysis by orlistat showed a decrease in the threshold for triolein in obese subjects (Pepino, Love-Gregory, Klein, \& Abumrad, 2012). Regarding the enzymes involved in lipolytic activity, the literature is quite scarce. Contrary to what was observed in rats with lingual lipase, no such specific salivary lipases were found in humans, suggesting a mechanism different to what occurs in rodents. Indeed, the expression of other lipases in minor salivary glands [von Ebner's gland (VEG)] was recently demonstrated (Voigt, et al., 2014) in human tongue tissue. However, the 
degree of lipid hydrolysis occurring with food in the human oral cavity has yet to be determined. Moreover, non-esterified fatty acids (NEFAs) are naturally present at low concentrations in high-fat foods, with the amount of NEFAs increasing further during oral processing such as eating (Mattes, 2009). More recently, Neyraud et al. (Neyraud, et al., 2017) examined fifty-four subjects and found a significantly positive correlation between lipolytic activity and FFA concentration, suggesting that lipolytic activity modulates the basal free fatty acid pattern in saliva. However, how the amount of FFA produced through salivary lipolysis or naturally present in the food might affect fat perception remains unresolved.

Free fatty acids are responsible for the tactile modality, which is modulated by salivary lipolytic activity.

\subsection{The tactile modality of fat perception}

The presence of fat in food is often associated with textural descriptors such as meltability, spreadability and greasy film (Di Monaco, et al., 2008; Martin, et al., 2016). It is worth mentioning that the relationship between fat liking and meltability is highly dependent on the type of product, as observed in the following examples. Margarines and table spreads of varying fat content $(20 \sim 80 \%)$ were ranked according to perceived meltability (Borwankar, Frye, Blaurock, \& Sasevich, 1992). The perceived meltability was not simply governed by the melting of fat but also by the rheology of the product. The cooling sensation accompanying melting was only perceived in the case of butter and other high-fat spread products. In the case of low-fat products, the cooling was imperceptible; thus, melting perception was related to the flowability. The cooling sensation has been long speculated as being one key characteristic that could differentiate between butter and margarine. A recent manuscript measured the differences in the cooling perception of spreads of different fat content and structure (Galindo-Cuspinera, Valença de Sousa, \& Knoop, 2017). The results confirmed that 
199

200

201

202

203

204

205

206

207

208

209

210

211

212

213

214

215

216

217

218

219

220

221

222

223

high-fat spreads, particularly butter, which contains a higher number of shorter chain fatty acids that melt at body temperature, convey a stronger cooling effect than low-fat margarines.

The rheology of these products is mainly governed by the phase volume fraction and droplet size. However, in the case of mixtures of different fat, it seems challenging to predict the texture perception of a mixture of fats from that of the fat itself. The physicochemical properties of a mixture of anhydrous milk fat and palm oil showed a non-linearity of hardness as a function of their respective ratios in the mixture, which was explained by changes in the polymorphic forms of fat attributed to different triacylglyceride intersolubilities (Danthine, 2012). Another parameter that seems to impact fat perception and liking is the particle size as observed for milk chocolate. The presence of large particles when using bound milk fat instead of free milk fat induced the perception of a "sandy mouthfeel", which decreased the overall liking (Bolenz, Thiessenhusen, \& Schape, 2003). Fat perception is also influenced by product viscosity. Schoumacker et al. (Schoumacker, et al., 2017) noticed that subjects could better discriminate cottage cheeses with different fat content at $15^{\circ} \mathrm{C}$ than at $7^{\circ} \mathrm{C}$, which was explained by differences in viscosity only present at the temperature of $15^{\circ} \mathrm{C}$.

The tactile modality of fat perception is a key driver of fat liking and depends on fat properties, product rheology and in-mouth process.

\subsection{Sensory interactions between fat and other oral sensory modalities}

Fat perception varies according to food composition but is also modified by other sensory modalities, due to the functional integration of information transmitted by the different chemical senses (Thomas-Danguin, 2009). Next, we will review the different types of oral sensory interactions involving fat perception. As only few examples could be found in the field of food spreads, some relevant examples of sensory interactions will be taken from other fatty food products. 
Binary taste-taste interactions have been studied in model systems between two of the five

227

taste qualities (sweet, salty, sour, bitter and umami) in model systems. These taste-taste interactions vary according to the different taste qualities of the components and their concentration (subthreshold or suprathreshold) (Keast \& Breslin, 2002). Very few studies report evidence for perceptual interactions between saltiness or sweetness and fat perception, while the impact of the fat content on salt release and saltiness perception has been shown in many studies. The main reason is probably that fat perception is complex and probably a multimodal sensation in itself. However, sodium chloride has a major impact on food structure, which then impacts both aroma release and texture perception, including fat perception.

The sensory interactions between saltiness and fatty perception have not been assessed in spreads, however some relevant effects have been found in dairy products. Working on model cheeses with different lipid/protein ratios and two-salt contents, Boisard et al. (Boisard, et al., 2014) found that model cheeses with added salt were perceived to be significantly more fatty regardless of the lipid/protein ratio. These cheeses were also less sticky, less elastic and less compact. However, there was no evidence regarding the saltiness-fattiness sensory interactions. The authors concluded that these model cheeses also contained larger fat globules (Boisard, et al., 2013), which could induce a higher mouth-coating responsible for fat perception and will also delay the transfer of aroma compounds with fatty notes and their release after swallowing, which could increase fatty aroma perception.

Sensory interaction between sweetness and fatty perception has been studied in different food products, showing that oral sensations generated by sugar and fat in familiar sugar/fat mixtures can influence the overall pleasantness of the food. However, the sensory interactions 
between sweetness and fat can vary according to the food product. It was observed that sugar may potentiate the oral perception of fat in liquid dairy products, by raising the stimulus viscosity and, thus, creaminess, whereas it masked oral perception in cakes (Drewnowski, 1993). Different results were observed by other authors. Working on biscuits, Biguzzi et al. (Biguzzi, Schlich, \& Lange, 2014) found that a reduction in the sugar content had no effect on fat perception, whereas a reduction in the fat content sometimes induced a lower sweetness perception. No significant effect of the addition of sugar in milk or yogurt was noticed on fat perception (Le Calve, et al., 2015). In addition to the products being different in the above studies, it must be mentioned that sensory preferences for sugar and fat in model dairy products showed considerable inter-individual variability. The following example shows differences in sensory preferences for fat and sugar according to the body weight status. Obese women gave highest pleasantness ratings to stimuli containing $34 \%$ fat and $4 \%$ sugar, while normal-weight women preferred stimuli with $20 \%$ fat and $9 \%$ sugar (Drewnowski, Brunzell, Sande, Iverius, \& Greenwood, 1985). Because the fat and sugar contents of food are predictive of the energy content, they activate common neural pathways for the reinforcement of behaviour. This activation leads to increased motivation to obtain high-fat/high-sugar foods and may reinforce energy intake and weight gain.

Concerning the sensory interactions with bitterness, Hayes and Duffy (Hayes \& Duffy, 2007, 2008) investigated the influence of the taste phenotype (PROP (6-n-propylthiouracil) bitterness) on the sweet and creamy sensations from sugar/fat milk-based mixtures (skim milk, whole milk and heavy cream). They found that fat and sweet liking depended on the subjects' PROP bitter sensitivity. The taster phenotype affects the degree of enhancement or suppression of sweetness and creaminess in liquid fat/sugar mixtures. For example, people who were more PROP sensitive rated creaminess higher than those who were less PROP sensitive, but only regarding heavy cream across all sucrose levels. As the fat level increased, 
the positive PROP-sweet relationship decreased (Hayes \& Duffy, 2007). Considering liking, it was observed that the fat and sugar levels for hedonic optima varied according to PROP sensitivity and/or the number of fungiform papillae. Women with many papillae exhibited optimal liking near 5\% fat and $12 \%$ sucrose with a high effect of fat content, whereas women with a low number of papillae were less sensitive to the fat content. Thus, individuals with a low number of papillae may be less able to use oral sensory cues to identify high-fat foods, and we can hypothesize that they would be better in accepting low-fat foods than individuals with a high number of papillae who might detect differences in products faster. In that study, PROP bitterness better explained variations in creaminess than the number of fungiform papillae. The authors justified this observation because creaminess was not merely a tactile event and there was also an odorant component (Hayes \& Duffy, 2007). This finding confirms that the olfactive component is important for global fat perception.

\subsubsection{Aroma-fat interactions}

Most of the studies dealing with the sensory interactions between aroma and other modalities are focused on the impact of aroma on taste perception, and only a few of them report results on the impact of aroma on texture perception (Thomas-Danguin, 2009). The quality of the aroma-taste interaction basically depends on the capacity of two stimuli to be appropriate for the combination in a food product (congruency) (Schifferstein \& Verlegh, 1996). Aromataste-integrated perception highly depends on learned associations, the context in which the food is consumed and the consumer's previous experience (Stevenson, Boakes, \& Prescott, 1998). Aroma-taste interactions have been extensively reported in model solutions and much lower in real-food samples. The impact of aroma on sweet perception has been extensively studied compared with other taste attributes, partly due to the common observation that certain odours smell "sweet". As an example, for the same sugar concentration, subjects 
299

300

301

302

303

304

305

306

307

308

309

310

311

312

313

314

315

316

317

318

319

320

321

322

323

perceived whipped cream with a strawberry aroma as being sweeter than whipped cream alone (Frank \& Byram, 1988). In custard desserts, it was also observed that a fruity aroma increased the sweet perception and vice versa, likely through cognitive mechanisms (Tournier, et al., 2009). Cross-modal interactions were also significantly reported for saltiness and aroma, mainly for lowering the salt content in foods while maintaining the saltiness intensity (Lawrence, et al., 2011). Only a few papers have reported on aroma-fat interactions. Syarifuddin et al. (Syarifuddin, Septier, Salles, \& Thomas-Danguin, 2016) studied aroma-fat and aroma-salt interactions in model cheeses varying in fat, salt and $\mathrm{pH}$ levels, in which sardine (salt-related) and butter (fat-related) aromas were added. Although the butter aroma intensity in the model cheeses was lower than the sardine aroma intensity, the butter aroma was found to have greater enhancement of fat perception than sardine aroma in the different model cheeses. Sardine aroma was found to induce higher saltiness enhancement in model cheeses with a low fat level. Moreover, the variation in texture did not affect fat perception but only saltiness. Bult et al. (Bult, de Wijk, \& Hummel, 2007) studied the interactions between cream aroma presented ortho- or retronasally and the oral texture (thickness and creaminess) of fresh milk with or without iota-carrageenan, using an air-dilution olfactometer.

The researchers reported that the odour stimulus increased the intensities of oral texture perception, such as thickness and creaminess, but only when the odour was presented retronasally, that is, as if the odour would have originated from the liquid. In real food products, multimodal interactions involving texture, taste and aroma perception occur and affect differently fat perception and liking. The release of two aroma compounds from six model cheeses differing in fat content and firmness was followed in relation to perception (Guichard, Repoux, Qannari, Labouré, \& Feron, 2017). The perception of blue cheese aroma (nonan-2-one) was not only explained by in vivo aroma release behaviour but also by the amount of fat remaining in the mouth, suggesting aroma-fat sensory interactions. 
This first section highlighted that global oral fat perception involves olfactive, gustative and tactile modalities and that these different modalities of fat perception interact together and with other oral sensory modalities. The next paragraph will present the oral physiological parameters that could be involved in fat perception and liking and could explain interindividual differences in fat perception and liking.

\section{Food oral processing and bolus formation in relation to fat perception}

Fat liking has been shown to be positively correlated with spreadability and fluidness and negatively with adhesiveness (Di Monaco, et al., 2008). Thus, bolus formation, structure and residence time are important factors in fat perception and liking. Most of the studies related to fat perception and liking reported great inter-individual variability, which could be mainly attributed to differences in oral physiology, saliva composition (Feron \& Poette, 2013; Poette, et al., 2014) and food oral processing (Guichard, et al., 2017). This finding emphasizes the key impact of food breakdown in the mouth and bolus formation on fat perception and liking. We will first present the in-mouth food breakdown leading to the formation of a food bolus, and then we will examine the specific role of saliva, followed by the other physiological activities involved in the different steps of oral processing.

\subsection{Food bolus structure}

Regarding food emulsions, the role of teeth and chewing in the oral processing of the food matrix can be considered negligible. The main events that contribute to in-mouth emulsion breakdown are shear forces due to the compression of the tongue and palate, tongue movements, heat transfer (melting) and interactions with saliva. These events will lead to the destabilisation of the emulsion through flocculation and coalescence phenomena. To date, most studies on food boluses describe ex vivo or in vitro experiments under conditions 
mimicking in-mouth processing and consider only a subset of the variables involved in the formation of the bolus. Thus, very few studies were conducted in vivo by describing the structure of the bolus just after spitting in humans, and most of them were performed on $\mathrm{O} / \mathrm{W}$ emulsions only.

The first indications on food bolus structure, after the spitting of emulsions, showed that in-mouth food breakdown leads to the formation of particles (droplets) whose size is dependent on the level of emulsion thickening, the thinnest product leading to the smallest droplet size (De Bruijne, Hendrickx, Anderliesten, \& De Looff, 1993). Moreover, O/W emulsions with mm-sized particles could be broken in the mouth into smaller droplets (20-30 $\mu \mathrm{m}$ ) by elongational flow (van Aken, Vingerhoeds, \& de Hoog, 2007). By contrast, Dresselhuis et al. showed that the coalescence of $\mathrm{O} / \mathrm{W}$ emulsions occurs in the mouth with the formation of droplets larger than $100 \mu \mathrm{m}$ for the lowest stabilized product (Dresselhuis, Stuart, van Aken, Schipper, \& de Hoog, 2008). This coalescence phenomenon depends on the stability of the emulsion but also on the individual. The role of the stabilizer has been recently confirmed. Emulsions stabilized with Na-caseinate showed no considerable change after mixing with saliva, while the opposite trend was observed for lysozyme-stabilised emulsions, regardless of the concentration of emulsifier used (Camacho, den Hollander, van de Velde, \& Stieger, 2015). However, in the mouth, emulsion coalescence depends not only on its stability but also on the solid fat content (SFC). High SFC emulsions show moderate coalescence scores, while medium SFC emulsions lead to a clear increase in the coalescence rating after oral processing (Benjamins, Vingerhoeds, Zoet, de Hoog, \& van Aken, 2009). A change in the emulsion structure after oral processing will modify viscosity properties. After the oral processing of emulsions with different stabilities, droplet aggregation leads to an increase in viscosity by a factor of 2-7 for reversibly flocculated whey protein isolate (WPI)-stabilised emulsions and a much larger factor, 15-30-fold, for an irreversibly flocculated lysozyme- 
374

375

376

377 378

379

380

381

382

383

384

385

386

387

388

389

390

391

392

393

394

395

396

397

398

stabilised emulsion. Such increases in viscosities are large enough to be perceived in the mouth. This observation provides indirect evidence for the sensory impact of the effect (van Aken, et al., 2007).

The way food is broken in the mouth impacts food bolus structure and thus tactile perception.

\subsection{Role of saliva in food bolus formation}

The multifunctional role of saliva as an unavoidable ingredient during the eating process has been recently reviewed, highlighting its surface coating and clustering properties, colloidal and enzymatic interactions, which may impact sensory perception (Mosca \& Chen, 2017). The amount of saliva incorporated contributes significantly to the change in the food bolus properties. Regarding fat emulsions and spreads, the level of moistening is both subject and product dependent. For instance, less saliva (20\%) is incorporated in light and ultra-light products than in spreads and butter (26-28\%). For subject effect, the amount of saliva incorporated ranges from $10 \%$ to $50 \%$ regardless of the matrix (light or fat). Regarding butter, the subjects were highly reproducible; however, for ultra-light products, an important intraindividual variability was observed (Feron, unpublished data). It is likely that these differences in oral processing have an impact on the food bolus structure with direct consequences on sensory perception and liking.

Saliva flow contributes mainly to the oral clearance of the mouth after food swallowing (Carpenter, 2012). The coating of food particles by the incorporation of saliva is necessary to form a bolus to be swallowed. Saliva stress in the mastication process has been estimated to be $50 \mathrm{~Pa}$, and foods with a higher yield stress cannot be broken up and dispersed with the saliva flow. Thus, the resulting perceived mouthfeel will be rather grainy, sticky, or waxy than smooth (De Bruijne, et al., 1993). Such behaviour was observed in the case of nut butter (Hawthornthwaite, Ramjan, \& Rosenthal, 2015; Rosenthal \& Share, 2014). The authors 
399

400

401

402

403

404

405

406

407

408

409

410

411

412

413

414

415

416

417

418

419

420

421

422

423

showed that the adsorption of water from the saliva gives rise to a sticky mass which coats the tongue and palate due to the presence of non-fat components within the spread (namely, dry complex carbohydrates and proteins).

Salivary viscosity has been estimated to be from $1 \mathrm{mPas}$ to $6 \mathrm{mPas}$ depending on the method of measurement (Schipper, Silletti, \& Vinyerhoeds, 2007). While suspected, the relationship between salivary viscosity and food bolus structure after oral processing of emulsions has not been formally demonstrated except through modelling approaches (De Bruijne, et al., 1993). However, experiments conducted in vitro on mayonnaises and custard with added artificial saliva containing mucin and not alpha-amylase failed to show any effect in friction properties, leading to the conclusion that no evidence was found that salivary mucins or salivary viscosity play a role in the lubrication of oral tissues (de Wijk \& Prinz, 2005).

Different saliva components might contribute to the destabilisation of $\mathrm{O} / \mathrm{W}$ emulsions during the oral processing of food and are considered important in fat detection. Some salivary proteins (mucins), enzymes (amylase) and ions have been suggested as key components in inmouth emulsion destabilisation. These components can provoke flocculation and coalescence by depletion phenomena and/or by electrostatic attraction and can hydrolyse the emulsion stabilisers (starch) located either at the surface of the oil droplets or in the continuous medium. However, these effects are related to the type and concentration of emulsifying proteins at the oil-water interfaces.

Vingerhoads et al. showed flocculation phenomena after mixing W/O emulsion with real saliva (Vingerhoeds, Blijdenstein, Zoet, \& van Aken, 2005). The researchers observed that these phenomena were subject and product dependent. Moreover, aggregation was observed with whole saliva but not with parotid saliva, suggesting the role of mucins as the main component in saliva responsible for the observed aggregation. This role of mucins on 
emulsion destabilisation was described recently in numerous studies. Altogether, these studies concluded that flocculation was caused by a depletion mechanism and that adsorption/association of mucins onto the emulsion droplets was related to the type of emulsifying proteins at the oil-water interfaces and probably driven by the overall net charge at the droplet's oil-water interfaces at neutral pH (Vingerhoeds, Silletti, de Groot, Schipper, \& van Aken, 2009; Silletti, Vitorino, Schipper, Amado, \& Vingerhoeds, 2010; Sarkar, Goh, \& Singh, 2009).

Alpha-amylase is the single most abundant protein in parotid saliva and a prominent component of whole-mouth saliva (Carpenter, 2012). The role of alpha-amylase can be twofold. First, alpha-amylase can associate with an emulsion favouring droplet aggregation, thus contributing to the modification of the food bolus structure and then texture perception (Silletti, et al., 2010). Second, alpha-amylase can hydrolyse food containing starch, resulting in a loss in viscosity of the product in the mouth (van Aken, et al., 2007). This action was observed on mayonnaise during in vitro experiments. The consequence is a higher lubrication due to a higher release of fat from the matrix after starch digestion by alpha-amylase (de Wijk \& Prinz, 2005; de Wijk, Prinz, Engelen, \& Weenen, 2004). Under in vivo conditions, preliminary results presented in a recent review showed significantly reduced stability when starch emulsions (but not caseinate emulsions) were mixed with saliva due to the enzymatic action of alpha-amylase (Chen, 2015). The authors also conclude that this colloidal destabilisation may lead to a rough and watery sensation.

It has been shown that interaction between emulsion droplets and saliva was not limited to mucins or alpha-amylase but also involves other salivary proteins in the molecular mass range of $10-100 \mathrm{kDa}$ such as polymeric Ig receptor and low-molecular-weight protein fractions (Silletti, et al., 2010). However, the large amount of salivary proteins associated with the droplets raises several questions regarding the nature of the interactions involved and nature 
of the proteins. In particular, proline-rich proteins (PRPs) are the most abundant proteins in stimulated saliva. With an isoelectric point of 4 or $9 / 10$ (depending the type of PRP), they can be either positively or negatively charged and, thus, can contribute significantly to droplet aggregation/repulsion.

In addition to proteins and enzymes, saliva is also rich in positively or negatively charged ions that could play a role in emulsion destabilization during oral processing. This role has been investigated by Sarkar et al. on $\mathrm{O} / \mathrm{W}$ emulsions with lactoferrin or beta-lactoglobulin as the interfacial layer (Sarkar, et al., 2009). The authors showed that lactoferrin-stabilized emulsion droplets (positively charged at the salivary $\mathrm{pH}$ ) showed considerable aggregation in the presence of salts (anionic) due to their screening effects. This salt-induced aggregation was reduced in the presence of mucin at different concentrations. Based on this result, the authors proposed an elegant mechanism describing the equilibrium between ions and mucins and droplet aggregation for lactoferrin-stabilised emulsion. Interestingly, this mechanism was not observed for the beta-lactoglobulin-stabilised emulsion, which is negatively charged at salivary $\mathrm{pH}$, suggesting a major role of anionic salts.

Salivary composition impacts food bolus structure which will affect tactile perception.

\subsection{Food oral processing in relation to bolus formation and fat perception}

This section will present the different steps of food oral processing with their associated physiological parameters and the resulting impact on fat perception.

\section{Tongue pressure and frictional effects}

Upon swallowing an emulsion, the tongue is pressed against the oral palate, producing a frictional effect (Malone, Appelqvist, \& Norton, 2003). The shear forces destabilize the emulsion in a product-dependent manner (oral-processing emulsions stabilised with less 
474

475

476

477

478

479

480

481

482

483

484

485

486

487

488

489

490

491

492

493

494

495

496

497

emulsifier resulted in larger coalescence phenomena). In contrast, although emulsions with solid fat (palm oil) had a greater tendency to make larger structures than emulsions with sunflower oil during in vitro experiments, this phenomenon was not observed in food bolus formation, likely because of the instantaneous melting of palm oil in the mouth (Dresselhuis, de Hoog, Stuart, Vingerhoeds, \& van Aken, 2008; Sarkar \& Singh, 2012). Thus, the role of tribology in the field of the oral processing of food is gradually gaining importance (Sarkar \& Singh, 2012). However, in situ measurements of the shear stress and rate are difficult to obtain; evaluation of these parameters has been attempted through sensory experiments on various products (Shama, Parkinson, \& Sherman, 1973; Shama \& Sherman, 1973). The authors concluded that a wide range of shear rates was involved, extending from approximately $10 \mathrm{~s}^{-1}$ to over $1000 \mathrm{~s}^{-1}$. The operative shear rate depended on the flow characteristics of the food, being much higher for viscous foods than for fluid foods. For example, the shear rates occurring in the mouth ranged from $5 \mathrm{~s}^{-1}$ for products such as hard margarine to $37 \mathrm{~s}^{-1}$ for more fluid products such as tomato ketchup (Malone, et al., 2003). In a similar study, 3 groups of sensory attributes were identified (Kokini, Kadane, \& Cussler, 1977). The first group, exemplified by "thickness", was closely associated with viscous force; the second group, characterized by "smoothness", was associated with the frictional force caused by contact between the tongue and roof of the mouth; the third group, as suggested by "slipperiness", was most closely associated with a combined force involving both frictional and viscous components.

Tongue pressure and frictional effects impact food bolus structure and fat perception differently according to food composition and structure.

Mouth coating and oral clearance 
Mouth coating is the result of the action of saliva, oral movement and swallowing due to the pressure of the tongue to the soft palate.

500 Evaluating oral coating after $\mathrm{O} / \mathrm{W}$ emulsion consumption is of high interest because it impacts

501 directly on the fatty after feel perception. Using O/W emulsions, Camacho et al (Camacho, van Riel, de Graaf, van de Velde, \& Stieger, 2014) concluded the following: (i) a direct positive relationship exists between the amount of lipid ingested and level of coating; (ii) a rapid oral clearance of the oral surfaces was observed after spitting; (iii) a higher coating was evident on the back of the tongue than on the front or lateral; and (iv) an important effect of the stabilizer and thickener was exerted on coating. In particular, the authors showed that emulsions with a higher thickener concentration rated higher on fattiness. This finding suggests that thickeners might create a lubricating layer on the tongue, thereby decreasing the friction and increasing fatty after-feel (Camacho, den Hollander, van de Velde, \& Stieger, 2015). For margarines differing on the level of fat and fat type (vegetal or mix), similar experiments were conducted using fluorescent probes (Poette, et al., 2014). Significant differences between products were observed regardless of the time of the measurement, with pure vegetal spreads coating the tongue more than the mix products. Moreover, high-fat spreads coated the tongue more than low-fat spreads, and the coating was higher at the back of the tongue than at the front and lateral parts. Finally, the oral clearance of fat was linked to 516 salivary flow. This is an interesting result showing similar tongue coating with w/o emulsion and $\mathrm{o} / \mathrm{w}$ emulsion. It is likely that the fatty after-feel after swallowing is also impacted.

518 Mouth coating and oral clearance depends on emulsion structure and impact fatty after feel 519 sensation. 
522 Surprisingly, the oral volume was rarely investigated in oral-processing behaviour, although it

523 may be the dominant factor in determining the exchange surface in the oral cavity. The oral

524 volume varies significantly among individuals with an overall mean of $38.6 \pm 10.5 \mathrm{~cm}^{3}$

525 (Feron, Ayed, Qannari, Courcoux, Laboure, et al., 2014). Regarding O/W emulsions, the oral

526 volume was directly and negatively correlated with fat sensitivity (Poette, et al., 2014). The

527 influence of the oral volume on sensory perception has already been highlighted for model

528 cheeses, showing a negative correlation between the oral volume and rate of aroma perception

529 (Guichard, et al., 2017), which was explained by a dilution effect.

530 The oral residence time of the product in the mouth has never been directly related to sensory

531 perception, but it depends on the product's properties. In the case of liquid or semi-liquid

532 food, the duration of oral processing is normally short. Considering 28 semi-solid products,

533 Chen and Lolivret showed an average oral residence time from $1.6 \mathrm{~s}$ for yoghurt to $7.7 \mathrm{~s}$ for

534 honey (Chen \& Lolivret, 2011), and Camacho et al. examined 25 subjects and found an

535 approximate value of $8 \mathrm{~s}$ for the oral residence time for $\mathrm{O} / \mathrm{W}$ emulsions (Camacho, Liu,

536 Linden, Stieger, \& Velde, 2015).

537 Oral volume impacts the dynamic of aroma release and the resulting olfactive modality of fat

538 perception.

539

540

Heat transfers and melting

541 The melting of emulsions in the mouth occurs immediately after ingestion of the product. It

542 results from the rapid transfer of heat from the mouth oral surface to the product, leading to

543 the perception of coolness (Galindo-Cuspinera, et al., 2017). Melting depends on the crystal

544 structure and nature of the fat in the product. In the case of spreads, melting leads to the

545 immediate inversion of the emulsion, from W/O to O/W. Indeed, it has been shown that if the

546 droplet size exceeds $30 \mu \mathrm{m}$ in diameter, some droplets will join to form channels or 'lakes'. 
547 Eventually, the water phase may become continuous during oral processing (i.e., inversion of

548 the emulsion may occur). On the other hand, if the water droplets are too small or are highly

549 stabilized, the phase inversion in the mouth under the influence of shear and added aqueous

550 phase (saliva) will not occur or will occur too slowly. Such spreads will have an unpleasant

551 gummy mouth feel. The cooling sensation because of melting fat will also be absent (Keogh,

552 2006). The melting rate and softening of margarines are directly linked to the level of

553 crystallised fat. Therefore, products containing more crystal fat will be perceived to melt

554 slower than products containing more liquid oil (Bot et al., 2003). Moreover, when high-

555 melting-point (above mouth $\mathrm{T}^{\circ}$ ) triglycerides (HMTs) are used in margarine or butter, they act

556 as a barrier that prevents the coalescence of droplets (Keogh, 2006). This point is particularly

557 relevant considering the in-mouth inversion phase of $\mathrm{W} / \mathrm{O}$ emulsions leading to $\mathrm{O} / \mathrm{W}$

558 emulsions because these HMTs will behave as solid particles (likely with different shapes and

559 sizes) floating in a liquid phase. This behaviour can lead to the perception of rough,

560 heterogeneous and granny attributes.

561 Melting depends on fat nature and impacts the tactile modality of fat perception.

562

563

564

565

566

567

568

569

570

571

572

2.4. Physiological parameters explaining interindividual differences in fat perception and liking

Due to the great impact of saliva on food bolus formation, inter-individual differences in saliva composition should impact fat perception. Engelen et al. investigated how variations in salivary characteristics affect the sensory perception of semi-solid products: in this case, mayonnaise and custard dessert by eighteen subjects (Engelen, et al., 2007). The results obtained for mayonnaise showed that a high salivary protein concentration is negatively associated with low oily and sour flavours, a thick and smooth texture, followed by sticky and fatty after feels. A high mucin level increased the heterogeneity and decreased the prickling mouth feel, and a high alpha-amylase activity induced a low prickling mouth feel and creamy 
573 after feel. High protein concentrations could possibly induce a decrease in the viscosity of the

574 product (through enzymatic breakdown), hindering the formation of a fatty layer on the

575 mucosa and leading to a low thickness sensation. The saliva composition can impact in-mouth

576 aroma release through enzymatic reactions occurring in the mouth between salivary proteins

577 and aroma compounds (Ployon, Morzel, \& Canon, 2017) or through hydrophobic interactions

578 as demonstrated in model systems between mucins or alpha-amylase and aroma compounds

579 (Canon, Pagès-Helary, \& Guichard, 2014; Pagès-Hélary, Andriot, Guichard, \& Canon, 2014).

580 If a decrease in aroma release has been demonstrated in the presence of salivary proteins, the

581 direct relationship between salivary protein concentration and aroma perception has not been

582 established yet.

583 Sensitivity to fat has also been related to the number of fungiform papillae (FP) present on the

584 tongue with potential consequences on fat intake (Nachtsheim \& Schlich, 2014). Individuals

585 with a high FP (HFP) count were more sensitive to the fat content and tended to consume less

586 fat than individuals with less FP (LFP) when evaluating high-fat margarine and milk. These

587 differences in the sensitivity to fat as related to the number of FP and how they correlate to

588 food intake were not observed for cheese or sausage. The authors suggested that FP could be

589 involved in modulating sensory attributes specific to spreads and milk such as creaminess and

590 melting. Interestingly, the authors showed a negative correlation between the salivary flow

591 (SF) and number of FP. This observation suggests that individuals with a low SF may have a

592 lower oral clearance after spread consumption, and, given the higher number of FP present,

593 these individuals are likely more sensitive to fatty/greasy attributes (Nachtsheim \& Schlich,

594 2014).

595 Differences in saliva composition and FP induce differences in fat perception.

596

597

\section{Conclusion}


Based on the information presented, a general mechanism can be proposed for the breakdown of spreads in the mouth leading to fat perception, involving first a melting phase, followed by an inversion phase and then bolus formation and swallowing (Figure 1).

Insert Figure 1

The melting phase begins as soon as the emulsion is placed in the mouth. In the case of W/O emulsions, the emulsion is inverted, and the progress of this inversion is driven by the physico-chemical properties of the fat, particularly the fat concentration, type of fat present and crystal structure. Thus, the solid fat content is an important parameter because it drives the cooling sensory descriptor, which appears to be an important attribute for product liking. In terms of physiological variables playing a role in the melting phase, it is difficult to find supporting data in the literature. However, we can propose that the oral volume and tongueplate compression contribute to favour heat transfer and, thus, to emulsion melting.

In the case of $\mathrm{W} / \mathrm{O}$ emulsions, the inversion phase often occurs at the same time as the melting phase, and the rate of this inversion is controlled mainly by the product's physicochemical properties, particularly the level of fat as well as emulsifiers and stabilizers. The difficulty is to find the good balance in terms of meltability and emulsion stability that would lead to a desirable mouthfeel. Having fat crystals that do not melt in the mouth will lead to a waxy feeling. Furthermore, if water droplet stability is too high, inversion does not occur, and the taste/aroma release will be affected. If the stability is too low, the inversion is too fast, and the creaminess will decrease. In addition to other physiological variables involved in the melting phase, a high salivary flow may favour moistening and, thus, inversion. At the end of this phase, we have an $\mathrm{O} / \mathrm{W}$ emulsion composed of fat, water, aroma and taste compounds, food additives and also a significant amount of salivary components. 
623 During bolus formation, which starts with the breakup of the emulsion in the mouth and

624

625

626

627

628

629

630

631

632

633

634

635

636

637

638

639

640

641

642

643

644

645

646 continues after phase inversion and until swallowing, oral processing events are similar to what is observed for $\mathrm{O} / \mathrm{W}$ emulsions. Food oral processing consists mainly of flocculation and coalescence phenomena, leading to a food bolus that is heterogeneous and viscous. These phenomena will directly impact sensory perception, particularly creaminess, roughness and fattiness and, thus, liking. In this phase, the role of the individual's physiology is highlighted, particularly the salivary flow (effect on oral coating), salivary viscosity (effect on droplet size) and some salivary components, such as alpha-amylase, mucins, ions (effect on droplet flocculation and coalescence) and PRP. Concerning the product, the fat level, quality, product stabilizers and thickeners are important for the emulsion breakup in this phase. However, aroma composition and, thus, aroma release during food oral processing are also important drivers of fat/spread perception and, thus, liking, as highlighted previously. Some aroma notes can contribute positively to liking (e.g., creamy and buttery), but others contribute negatively to liking (e.g., greasy notes). The dynamic of aroma release that depends on the solid fat content (the higher the solid fat content is, the slower the aroma release is) and the dynamic of the amount of product remaining in the mouth are drivers of the dynamics of perception. Controlling the release of the different aroma compounds during bolus formation and swallowing will lead to a well-balanced aroma perception, contributing positively to liking. The remanence of off-flavour aroma compounds in the mouth will contribute to an undesirable after taste and a low liking. Most importantly, the interactions among the different perceptual modalities (texture, taste, aroma, appearance and perhaps even sound) involved in fat perception must be considered for the global acceptability of fat-containing products.

\section{Future trends}


647 The main outcome from this review is that consumer segmentation from a physiological view

648 should be primarily based on the melting and inversion phases for $\mathrm{O} / \mathrm{W}$ emulsions because,

649 together, they constitute the first dynamic events when the product is placed into the mouth

650 and contribute to the emulsion breakup, leading to the first sensory sensations. Considering

651 the previous conclusion and limited work published in this area, there is a need for a thorough

652 investigation of the melting and inversion phases that play a crucial role in bolus formation

653 with consequences in sensory perception and liking. In particular, the relationship between the

654 melting phase, inversion phase, cooling perception, nature and structure of the fat phase and

655 how they affect the emulsion breakup and oral behaviour needs to be explored through a

656 mechanistic approach at different levels, from the molecular to the more global oral system.

657 This investigation can allow prioritization of the different physiological oral characteristics

658 (oral volume, oral surface exchanges) that drive this step and explain inter-individual 659 consumer differences.

660 A secondary outcome is that mouth feel is another important sensory sensation contributing to

661 the global liking of the product. Mouth feel is highly related to mouth coating and oral

662 clearance. Thus, there is a need to investigate deeply the mechanisms occurring during bolus

663 formation and how differences in physiology affect mouth coating and clearance. While

664 several literature reports have been published on the role of saliva in perception, the relative

665 impact of salivary proteins, fungiform papilla, salivary flow, mucosal pellicle and PROP

666 sensitivity on fat liking has not been fully elucidated yet.

667 Third, understanding the olfactory contribution to fat perception should account for the

668 different aroma molecules with fatty notes, their molecular interactions with fat, salivary

669 proteins and impact of food oral processing on dynamic aroma release and dynamic sensory

670 perception. 
671 Finally, fat should be considered as a multimodal perception; thus, the relative contribution of

672 the different modalities (olfactive, gustative and tactile) underlying to fat liking must be

673 unravelled. Due to the growing development of cognitive neurosciences to unravel

674 multisensory integration, the mechanisms leading to multimodal interaction could now be

675 envisaged at the central level. Brain imaging approaches could provide better insights into our

676 understanding of the brain processes implied in multimodal interactions and their impact on

677 the holistic perception of flavour and subsequent liking.

678

679

Aknowledgements

680

This work was supported by Unilever R\&D Vlaardingen.

681

682

\section{References}

683

684

685

686

687

688

689

690

691

692

693

694

695

696

697

698

699

700

701

702

703

704

705

706

707

708

Benjamins, J., Vingerhoeds, M. H., Zoet, F. D., de Hoog, E. H. A., \& van Aken, G. A. (2009). Partial coalescence as a tool to control sensory perception of emulsions. Food Hydrocolloids, 23, 102-115.

Biguzzi, C., Schlich, P., \& Lange, C. (2014). The impact of sugar and fat reduction on perception and liking of biscuits. Food Quality and Preference, 35, 41-47.

Boisard, L., Andriot, I., Arnould, C., Achilleos, C., Salles, C., \& Guichard, E. (2013). Structure and composition of model cheeses influence sodium NMR mobility, kinetics of sodium release and sodium partition coefficients. Food Chemistry, 136, 1070-1077.

Boisard, L., Andriot, I., Martin, C., Septier, C., Boissard, V., Salles, C., \& Guichard, E. (2014). The salt and lipid composition of model cheeses modifies in-mouth flavour release and perception related to the free sodium ion content. Food Chemistry, 145, 437-444.

Bolenz, S., Thiessenhusen, T., \& Schape, R. (2003). Fast conching for milk chocolate. European Food Research and Technology, 218, 62-67.

Borwankar, R. P., Frye, L. A., Blaurock, A. E., \& Sasevich, F. J. (1992). Rheological characterization of melting of margarines and tablespreads Journal of Food Engineering, 16, 55-74.

Bult, J. H. F., de Wijk, R. A., \& Hummel, T. (2007). Investigations on multimodal sensory integration: Texture, taste, and ortho- and retronasal olfactory stimuli in concert. Neuroscience Letters, 411, 6-10.

Camacho, S., den Hollander, E., van de Velde, F., \& Stieger, M. (2015). Properties of Oil/Water Emulsions Affecting the Deposition, Clearance, and After-Feel Sensory Perception of Oral Coatings. Journal of Agricultural and Food Chemistry, 63, 2145-2153.

Camacho, S., Liu, K., Linden, A., Stieger, M., \& Velde, F. (2015). Formation, Clearance and Mouthfeel Perception of Oral Coatings Formed by Emulsion-Filled Gels. Journal of Texture Studies.

Camacho, S., van Riel, V., de Graaf, C., van de Velde, F., \& Stieger, M. (2014). Physical and Sensory Characterizations of Oral Coatings of Oil/Water Emulsions. Journal of Agricultural and Food Chemistry, 62, 5789-5795. 
Canon, F., Pages-Helary, S., \& Guichard, E. (2014). In nose concentration of aroma compounds is modified by salivary protein composition and saliva stimulation. In Chemical Senses (Ed.), The 24th Congress of the European Chemoreception Research Organisation (ECRO) in Dijon (France) (Vol. 40, pp. 237-237). Oxford (England): Oxford University Press.

Carpenter, G. (2012). Role of saliva in the orla processing of food. In J. Chen, Engelen, L. (Ed.), Food Oral Processing (pp. 45-62): Wiley-Blackwell.

Chale-Rush, A., Burgess, J. R., \& Mattes, R. D. (2007). Evidence for human orosensory (taste ?) sensitivity to free fatty acids. Chemical Senses, 32, 423-431.

Charles, M., Martin, B., Ginies, C., Etiévant, P., Costello, C. E., \& Guichard, E. (2000). Potent aroma compounds of two red wine vinegars. Journal of Agricultural and Food Chemistry, 48, 70-77.

Charles, M., Rosselin, V., Sauvageot, F., Beck, L., \& Guichard, E. (2000). Sensory and physico-chemical approaches to flavour release from salad dressings in relation to the structure.

Chen, J. (2015). Food oral processing: mechanisms and implications of food oral desctruction. Trends in Food Science \& Technology.

Chen, J., \& Lolivret, L. (2011). The determining role of bolus rheology in triggering a swallowing. Food Hydrocolloids, 25, 325-332.

Coic, S., Groeneschild, C., \& Tournier, C. (2014). Role of aroma-matrix interactions on perception of structured emulsions. In V. Ferreira \& R. Lopez (Eds.), Flavour Science (pp. 159-163): Elsevier.

Danthine, S. (2012). Physicochemical and structural properties of compound dairy fat blends. Food Research International, 48, 187-195.

De Bruijne, D., Hendrickx, H., Anderliesten, L., \& De Looff, J. (1993). Mouthfeel of foods. In E. D. \& P.W. (Eds.), Food colloids and polymers: stability and mechanical properties. Cambridge: Royal Society of Chemistry.

de Wijk, R. A., \& Prinz, J. F. (2005). The role of friction in perceived oral texture. Food Quality and Preference, 16, 121-129.

de Wijk, R. A., Prinz, J. F., Engelen, L., \& Weenen, H. (2004). The role of alpha-amylase in the perception of oral texture and flavour in custards. Physiology \& Behavior, 83, 81-91.

Di Monaco, R., Giancone, T., Cavella, S., \& Masi, P. (2008). Predicting texture attributes from microstructural, rheological and thermal properties of hazelnut spreads. Journal of Texture Studies, 39, 460-479.

Dresselhuis, D. M., de Hoog, E. H. A., Stuart, M. A. C., Vingerhoeds, M. H., \& van Aken, G. A. (2008). The occurrence of in-mouth coalescence of emulsion droplets in relation to perception of fat. Food Hydrocolloids, 22, 1170-1183.

Dresselhuis, D. M., Stuart, M. A. C., van Aken, G. A., Schipper, R. G., \& de Hoog, E. H. A. (2008). Fat retention at the tongue and the role of saliva: Adhesion and spreading of 'protein-poor' versus 'protein-rich' emulsions. Journal of Colloid and Interface Science, 321, 21-29.

Drewnowski, A. (1993). Individual differences in sensory preferences for fat in modle sweet dairy products. Acta Psychologica, 84, 103-110.

Drewnowski, A., Brunzell, J. D., Sande, K., Iverius, P. H., \& Greenwood, M. R. C. (1985). Sweet tooth reconsidered - taste responsiveness in human obesity. Physiology \& Behavior, 35, 617-622.

Engelen, L., van den Keybus, P. A. M., de Wijk, R. A., Veerman, E. C. I., Amerongen, A. V. N., Bosman, F., Prinz, J. F., \& van der Bilt, A. (2007). The effect of saliva composition on texture perception of semi-solids. Archives of Oral Biology, 52, 518-525.

Feron, G., Ayed, C., Qannari, E. M., Courcoux, P., Labouré, H., \& Guichard, E. (2014). Understanding aroma release from model cheeses by a statistical multiblock approach on oral processing. PLoS One, 9, 1-15.

Feron, G., \& Poette, J. (2013). In-mouth mechanism leading to the perception of fat in humans: from detection to preferences. The particular role of saliva. OCL - Oleagineux Corps Gras Lipides, 20, 102-107.

Frank, R. A., \& Byram, J. (1988). Taste and smell interactions are tastant and odorant dependant Chemical Senses, 13, 445-455. 
Galindo-Cuspinera, V., Valença de Sousa, J., \& Knoop, M. (2017). Sensory and analytical characterization of the "cool-melting" perception of commercial spreads. Journal of texture studies, 48, 302-3012.

Gaviao, M. B. D., Engelen, L., \& van der Bilt, A. (2004). Chewing behavior and salivary secretion. European Journal of Oral Sciences, 112, 19-24.

Guichard, E. (2002). Interactions between flavor compounds and food ingredients and their influence on flavor perception. Food Reviews International, 18, 49-70.

Guichard, E., Fabre, M., \& Relkin, P. (2008). Flavor release from food emulsions varying in their composition in fat and proteins and its effect on flavor perception. American Laboratory, 40, 13-17.

Guichard, E., Repoux, M., Qannari, E. M., Labouré, H., \& Feron, G. (2017). Model cheese aroma perception is explained not only by in vivo aroma release but also by salivary composition and oral processing parameters. Food \& Function, 8, 615-628.

Hayes, J. E., \& Duffy, V. B. (2007). Revisiting sugar-fat mixtures: Sweetness and creaminess vary with phenotypic markers of oral sensation. Chemical Senses, 32, 225-236.

Hayes, J. E., \& Duffy, V. B. (2008). Oral sensory phenotype identifies level of sugar and fat required for maximal liking. Physiology \& Behavior, 95, 77-87.

Heinze, J. M., Preissl, H., Fritsche, A., \& Frank, S. (2015). Controversies in fat perception. Physiology \& Behavior, 152, 479-493.

Jelen, H., \& Gracka, A. (2017). Characterization of aroma compounds: structure, physico-chemical and sensory properties. In E. Guichard, C. Salles, M. Morzel \& A. M. Le Bon (Eds.), Flavour, from food to perception (pp. 126-153). Chichester, UK: Wiley Blackwell.

Keast, R. S. J., \& Breslin, P. A. S. (2002). An overview of binary taste-taste interactions. Food Quality and Preference, 14, 111-124.

Keogh, M. (2006). Chemistry and technology of butter and milk fat spreads. In P. F. Fox \& P. L. H. McSweeney (Eds.), Advanced Dairy Chemistry Volume 2 Lipids (pp. 333-363). Boston, MA: Springer US.

Kokini, J. L., Kadane, J. B., \& Cussler, E. L. (1977). Liquid texture perceived in mouth. Journal of Texture Studies, 8, 195-218.

Krause, A. J., Lopetcharat, K., \& Drake, M. A. (2007). Identification of the characteristics that drive consumer liking of butter. Journal of Dairy Science, 90, 2091-2102.

Laboure, H., Repoux, M., Courcoux, P., Feron, G., \& Guichard, E. (2014). Inter-individual retronasal aroma release variability during cheese consumption: Role of food oral processing. Food Research International, 64, 692-700.

Lawrence, G., Salles, C., Palicki, O., Septier, C., Busch, J., \& Thomas-Danguin, T. (2011). Using crossmodal interactions to counterbalance salt reduction in solid foods. International Dairy Journal, 21, 103-110.

Le Calve, B., Saint-Leger, C., Babas, R., Gelin, J. L., Parker, A., Erni, P., \& Cayeux, I. (2015). Fat Perception: How Sensitive are We? Journal of Texture Studies, 46, 200-211.

Leffingwell. (2013). Flavor-Base 9th Ed. In. http://www.leffingwell.com/flavbase.htm Leffingwell \& Associates.

Malone, M. E., Appelqvist, I. A. M., \& Norton, I. T. (2003). Oral behaviour of food hydrocolloids and emulsions. Part 1. Lubrication and deposition considerations. Food Hydrocolloids, 17, 763773.

Martin, C., Schoumacker, R., Bourjade, D., Thomas-Danguin, T., Guichard, E., Le Quéré, J.-L., \& Labouré, H. (2016). Sensory properties linked to fat content and tasting temperature in cottage cheese. Dairy Science \& Technology, 96, 735-746.

Mattes, R. D. (2009). Is There a Fatty Acid Taste? In Annual Review of Nutrition (Vol. 29, pp. 305327).

Michicich, M., Vickers, Z., Martini, M. C., \& Labat, J. B. (1999). Consumer acceptance, consumption and sensory attributes of spreads made from designer fats. Food Quality and Preference, 10, 147-154. 
Mosca, C., \& Chen, J. (2017). Food-saliva interactions: mechanisms and implications. Trends in Food Science \& Technology, 66, 125-134.

Mounayar, R., Septier, C., Chabanet, C., Feron, G., \& Neyraud, E. (2013). Oral Fat Sensitivity in Humans: Links to Saliva Composition Before and After Stimulation by Oleic Acid. Chemosensory Perception, 6, 118-126.

Nachtsheim, R., \& Schlich, E. (2014). The influence of oral phenotypic markers and fat perception on fat intake during a breakfast buffet and in a 4-day food record. Food Quality and Preference, 32, Part C, 173-183.

Neyraud, E., Cabaret, S., Brignot, H., Chabanet, C., Labouré, H., Guichard, E., \& Berdeaux, O. (2017). The basal free fatty acid concentration in human saliva is related to salivary lipolytic activity. Scientific reports, 7: 5969.

Neyraud, E., Palicki, O., Schwartz, C., Nicklaus, S., \& Feron, G. (2012). Variability of human saliva composition: Possible relationships with fat perception and liking. Archives of Oral Biology, 57, 556-566.

Pagès-Hélary, S., Andriot, I., Guichard, E., \& Canon, F. (2014). Retention effect of human saliva on aroma release and respective contribution of salivary mucin and $\alpha$-amylase. Food Research International, 64, 424-431.

Pagès-Hélary, S., Guichard, E., \& Canon, F. (2015). Is aroma release affected by salivary composition? In A. J. Taylor \& D. S. Mottram (Eds.), Flavour science, proceedings of the 14th Weurman Flavour Research Symposium (pp. 321-326). Leicestershire (United kingdom): Context Products Ltd.

Pepino, M. Y., Love-Gregory, L., Klein, S., \& Abumrad, N. A. (2012). The fatty acid translocase gene CD36 and lingual lipase influence oral sensitivity to fat in obese subjects. Journal of Lipid Research, 53, 561-566.

Pivk, U., Godinot, N., Keller, C., Antille, N., Juillerat, M.-A., \& Raspor, P. (2008). Lipid Deposition on the Tongue after Oral Processing of Medium-Chain Triglycerides and Impact on the Perception of Mouthfeel. Journal of Agricultural and Food Chemistry, 56, 1058-1064.

Ployon, S., Morzel, M., \& Canon, F. (2017). The role of saliva in aroma release and perception. Food Chemistry, 226, 212-220.

Poette, J., Lubbers, S., Maison, B., Andriot, I., Pernin, K., Guichard, E., Cavellec, A., \& Feron, G. (2010). The salivary reactor: an innovating tool for the categorization of food products through their aroma and taste compounds release profiles. In T. Hofmann, W. Meyerhof \& P. Schieberle (Eds.), Advances and challenges in flavor chemistry \& biology._Proceedings of the 9th Wartburg Symposium (pp. 386-389). Freising (Germany): Deutsche Forschungsanstalt für Lebensmittelchemie.

Poette, J., Mekoue, J., Neyraud, E., Berdeaux, O., Renault, A., Guichard, E., Genot, C., \& Feron, G. (2014). Fat sensitivity in humans: oleic acid detection threshold is linked to saliva composition and oral volume. Flavour and Fragrance Journal, 29, 39-49.

Repoux, M., Laboure, H., Courcoux, P., Andriot, I., Semon, E., Yven, C., Feron, G., \& Guichard, E. (2012). Combined effect of cheese characteristics and food oral processing on in vivo aroma release. Flavour and Fragrance Journal, 27, 414-423.

Roudnitzky, N., Irl, H., Roudaut, G., \& Guichard, E. (2003). Influence of fat nature on flavour release. In J. L. Le Quere \& P. X. Etiévant (Eds.), Flavour research at the dawn of the twenty-first century (pp. 136-139). Paris (France): Lavoisier Tec \& Doc.

Running, C. A., \& Mattes, R. D. (2016). A Review of the Evidence Supporting the Taste of Nonesterified Fatty Acids in Humans. Journal of the American Oil Chemists Society, 93, 13251336.

Sarkar, A., Goh, K., \& Singh, R. (2009). Colloidal stability and interactions of milk-protein-stabilized emulsions in an artificial saliva. Food Hydrocolloids, 23, 1270-1278.

Sarkar, A., \& Singh, H. (2012). Oral Behaviour of Food Emulsions. In J. Chen \& L. Engelen (Eds.), Food Oral Processing (pp. 111-137). UK: Wiley-Blackwell. 
Schifferstein, H. N. J., \& Verlegh, P. W. J. (1996). The role of congruency and pleasantness in odorinduced taste enhancement. Acta Psychologica, 94, 87-105.

Schiffman, S. S., Graham, B. G., Sattely-Miller, E. A., \& Warwick, Z. S. (1998). Orosensory perception of dietary fat. Current Directions in Psychological Science, 7, 137-143.

Schipper, R., Silletti, E., \& Vinyerhoeds, M. (2007). Saliva as research material: biochemical, physicochemical and practical aspects. Archives of Oral Biology, 52, 1114-1135.

Schoumacker, R., Martin, C., Thomas-Danguin, T., Guichard, E., Le Quéré, J.-L., \& Labouré, H. (2017). Fat perception in cottage cheese: The contribution of aroma and tasting temperature. Food Quality and Preference, 56, 241-246.

Shama, F., Parkinson, C., \& Sherman, P. (1973). Identification of stimuli controlling the sensory evaluation of viscosity. I. Non-oral methods. Journal of Texture Studies, 4, 102-110.

Shama, F., \& Sherman, P. (1973). Identification of stimuli controlling the sensory evaluation of viscosity. II. Oral methods. Journal of Texture Studies, 4, 111-118.

Silletti, E., Vitorino, R. M. P., Schipper, R., Amado, F. M. L., \& Vingerhoeds, M. H. (2010). Identification of salivary proteins at oil-water interfaces stabilized by lysozyme and beta-lactoglobulin. Archives of Oral Biology, 55, 268-278.

Spence, C., et al. (2010). Does Food Color Influence Taste and Flavor Perception in Humans? Chemosensory Perception, 3(1), 68-84.

Spence, C. (2015). Multisensory Flavor Perception. Cell, 161(1), 24-35.

Stevenson, R. J., Boakes, R. A., \& Prescott, J. (1998). Changes in odor sweetness resulting from implicit learning of a simultaneous odor-sweetness association: An example of learned synesthesia. Learning and Motivation, 29, 113-132.

Stewart, J. E., Feinle-Bisset, C., \& Keast, R. S. J. (2011). Fatty acid detection during food consumption and digestion: Associations with ingestive behavior and obesity. Progress in Lipid Research, 50, 225-233.

Syarifuddin, A., Septier, C., Salles, C., \& Thomas-Danguin, T. (2016). Reducing salt and fat while maintaining taste: An approach on a model food system. Food Quality and Preference, 48, 59-69.

Thomas-Danguin, T. (2009). Flavor. In M. D. Binder, N. Hirokawa \& U. Windhorst (Eds.), Encyclopedia of Neuroscience (4399 p.) (pp. version électronique). Berlin Heidelberg (Deutschland): Springer-Verlag $\mathrm{GmbH}$.

Thomsen, M., Martin, C., Mercier, F., Tournayre, P., Berdague, J.-L., Thomas-Danguin, T., \& Guichard, E. (2012). Investigating semi-hard cheese aroma: Relationship between sensory profiles and gas chromatography-olfactometry data. International Dairy Journal, 26, 41-49.

Tournier, C., Sulmont-Rossé, C., Sémon, E., Vignon, A., Issanchou, S., \& Guichard, E. (2009). A study on texture-taste-aroma interactions: physico-chemical and cognitive mechanisms. International Dairy Journal, 19, 450-458.

Tucker, R. M., Kaiser, K. A., Parman, M. A., George, B. J., Allison, D. B., \& Mattes, R. D. (2017). Comparison of fatty acid taste detection thresholds in people who are lean vs. overweight or obese: a systematic review and meta-analysis. PLoS One, 12, e0169583.

van Aken, G. A., Vingerhoeds, M. H., \& de Hoog, E. H. A. (2007). Food colloids under oral conditions. Current Opinion in Colloid \&amp; Interface Science, 12, 251-262.

van den Oever, G. J. (2006). Fat reduction in foods: Microstructure control of oral texture, taste, and aroma in reduced oil systems. In F. Shahidi \& H. Weenen (Eds.), Food Lipids: Chemistry, Flavor, and Texture (Vol. 920, pp. 171-189).

Vingerhoeds, M. H., Blijdenstein, T. B. J., Zoet, F. D., \& van Aken, G. A. (2005). Emulsion flocculation induced by saliva and mucin. Food Hydrocolloids, 19, 915-922.

Voigt, N., Stein, J., Galindo, M. M., Dunkel, A., Raguse, J. D., Meyerhof, W., Hofmann, T., \& Behrens, M. (2014). The role of lipolysis in human orosensory fat perception. Journal of Lipid Research, $55,870-882$.

Wadhwani, R. and D. J. McMahon (2012). Color of low-fat cheese influences flavor perception and consumer liking. Journal of Dairy Science, 95(5), 2336-2346. 
921 Figure caption

922 Figure 1: proposed mechanisms describing the different oral events occurring during 923 consumption of spread and their putative impact on sensory attributes. 
Melting phase

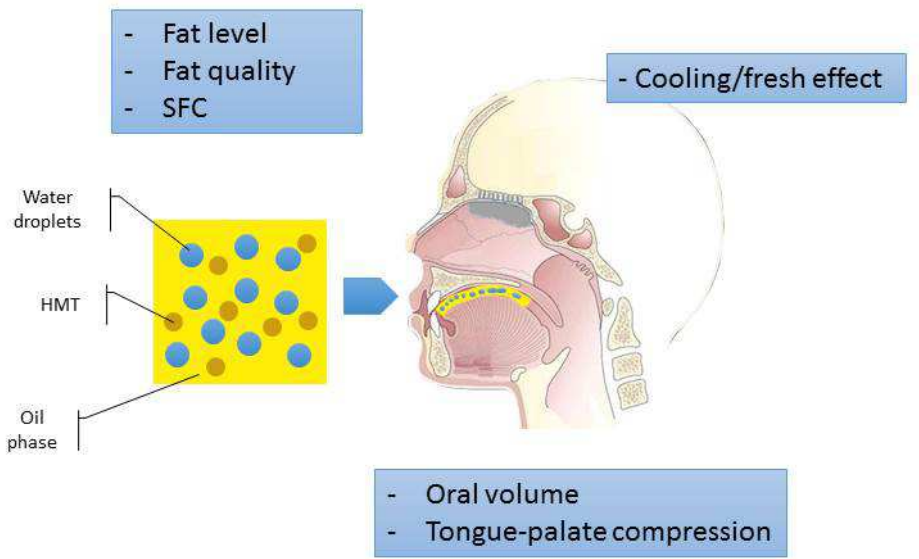

Inversion phase
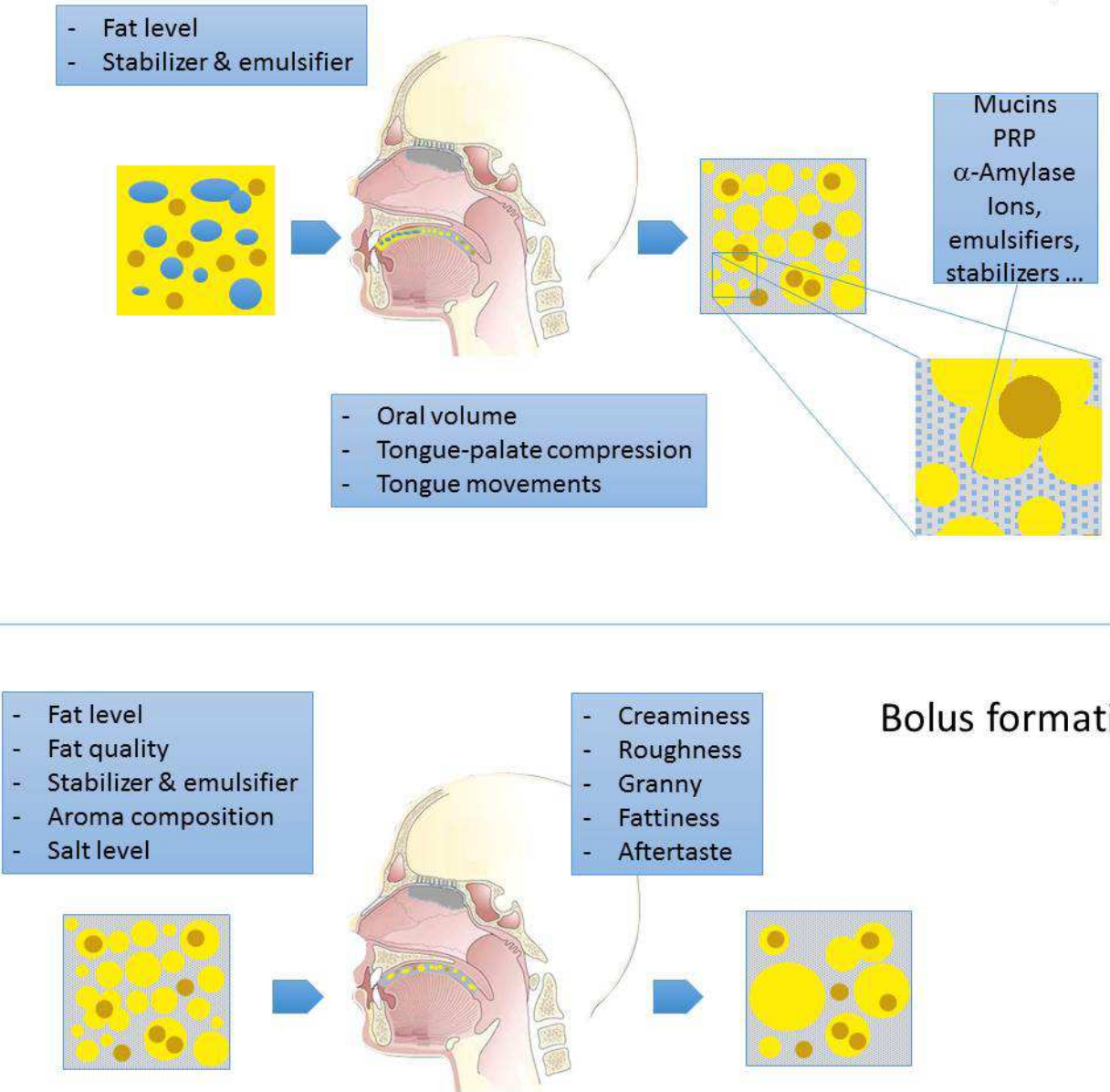

- Tongue movements

- Saliva flux \& viscosity

- Saliva composition (mucins, ions, $\alpha$-amylase, PRP)

- Fungiform papillae 